\title{
Farm Education and The Effect of a Farm Visit on Children's Conception of Agriculture
}

\author{
Pia Smeds* \\ Natural Resources Institute, FINLAND
}

\author{
Eila Jeronen \\ University of Oulu, FINLAND
}

\author{
Sirpa Kurppa \\ Natural Resources Institute, FINLAND
}

\begin{abstract}
Personal connections to agriculture have decreased considerably in Finland during the last few decades due to structural changes in agriculture. In this study, we will elucidate the understanding and conception of agriculture amongst urban pupils who have grown up during the 21st century. The research strategy consists of intervention in form of a farm visit, with pre- and postassessment. The methods for collecting data were drawings for gaining a diversified understanding of how pupils understand, experience and conceptualize agriculture. The drawings were analyzed by visual content analysis. In addition, interviews, analyzed by inductive content analysis method, were used to clarify the results. Qualities of farms as authentic learning environments are defined and studied The study revealed that many pupils had irrational conceptions of agriculture before the farm visit (38 \%), but decreased significantly after the visit. One of the explaining factors for these irrational conceptions was considered to be the influence of media sources. Farms as educational learning environments were able to correct pupils' false conceptions. A realistic image of agriculture is of significant value for becoming an aware and responsible consumer as well as choosing a career in agriculture.
\end{abstract}

Keywords: Agriculture, farm visit, media, conception, intervention, drawings, interviews

To cite this article: Smeds, P., Jeronen, E. \& Kurppa, S. (2015). Farm Education and The Effect of a Farm Visit on Children's Conception of Agriculture. European Journal of Educational Research, 4(1), 1-13. doi: 10.12973/eu-jer.4.1.1

\section{Introduction}

Citizens of today's rural and urban societies, in Finland as well as internationally, are gaining a distance spatially, socially as well as culturally to agriculture. Agriculture has been practised in Finland for more than 4000 years (Rasila, Jutikkala and Mäkelä-Alitalo, 2003), and it is part of the Finnish cultural heritage. But in 1950-1975 Finland followed the same process as most Western countries and developed from an agricultural society to an industrialised one (Ahonen, 2003). The number of farms has declined ever since, as larger efficient units are formed and technical development is replacing farm labour. A significant drop took place between 1995 and 2010 due to structural changes in agriculture, when the number of active farms dropped by $37 \%$ (Maatilatilastollinen Vuosikirja, 2011).

In other words, 50 years ago, most Finns had relatives on farms or had other social contacts with agriculture and were able to genuinely experience agriculture and a farm culture. Today's growing generation has infrequent or no contacts at all with agriculture. This might be one of the reasons why urban Finnish children have been found to express romanticised images of agriculture (Smeds et al., 2011). According to international studies, pupils in many countries also have insufficient knowledge of agriculture (Mabie \& Baker, 1994; Trexler, 2000).
Agriculture and the history of agriculture is a part of the Finnish National Core Curriculum for Basic Education (2004) (later referred to as NCC) and is in many schools taught in the $4^{\text {th }}$ grade, when the pupils are 10 years old. In addition, children have other sources of information in their surroundings. Media, books, the Internet and magazines are thought to influence pupils' perceptions (Gardner, 1980; Palmer, 1998; Stenbacka, 2011). Stenbacka (2011, 243) has studied how Swedish media portray rural people and rural masculinity. She discussed the way in which popular television series (e.g. "The farmer wants a wife", in Finnish "Maajussille morsian") have a tendency to portray farmers or rural males as "...unequal, incapable and deviant, the urban man represents the unspoken opposites: equal, capable and constituting the norm." Children's books do also at times portray humorous images of rural professions. The media may create an image of rural people that is entertaining, but untrue and based on anecdotes. This is problematic, as the media in these cases promotes a gap between rural and urban, causes geographical labelling and fosters traditionalism (Stenbacka, 2011).

An authentic learning environment was chosen as it enables pupils to study in the genuine environment for the subject to be learned and offers first-hand experiences, activities and knowledge by its authentic actors. Farms were chosen as they are decreasing in

\footnotetext{
* Corresponding author:

Pia Smeds, Natural Resources Institute, Finland

Email: pia.smeds@luke.fi, pia.smeds@mtt.fi
} 
number and pupils' natural contact to them is scarce. Yet knowledge of farms and agriculture is important, as they are the main source for primary food production. Food is a subject that we need to make choices on every day, for our health, the environment and climate. In this study we want to find out what kind of conception urban pupils in the $5^{\text {th }}$ grade (11-year-old pupils) have of Finnish agriculture and how a visit to a farm, an authentic learning environment, affects this conception. A pupil's conception is in this study understood as his or her personal idea of what they think a farm looks like, what agriculture includes and who a farmer is as a human being and professional man. Urbanity was here defined as a town with 60,000 inhabitants. Research method is experiential with farm visits as an intervention. Data collection methods used is subject-produced drawings and interviews and analysis methods are content analysis.

\section{Theoretical Background}

Farms and gardens used for educational purposes have a rising tendency in many European countries, but research on their educational quality is scarce. Smeds et al. (2011) developed various educational programmes based on educational theories and the NCC for the farm environment. They studied pupils' expectations and experiences and teacher's experiences within these programmes. This study goes one step further and studies the educational outcomes of using farms as an authentic learning environment as well as Farm education as a concept.

The authentic on farm learning environment is anchored in theoretical background of environmental education (EE). EE can be seen as a learning process that by the help of the environment allows pupils to gain comprehension, ability, experience and values of the chosen environment. One step further is to foster the pupils' self-efficacy (Bandura, 1997) to act according to their knowledge and attitudes. EE is a phenomenon that has been important in the Nordic education, for example the Swedish botanist and lecturer Carl Linnaeus (Carl von Linné) took his students on regular field trips for experiencing the plants in their real environment. Learning in such an environment allows pupils to use of different senses in the learning process, which has been found in research to improve learning (Dahlgren \& Szczepanski, 1997; McRae, 1990; Palmberg \& Kuru, 2000). The contemporary EE can be seen to have its roots in the Belgrade Charter (UNESCO-UNEP, 1976) and the Tbilisi Declaration (UNESCO, 1978). The former defines the common ground for EE and the latter takes EE further with recommendations and criteria for education on all levels as well as formal and informal education. In this article we utilize the EE model (Palmer \& Neal, 1994; Palmer, 1998) and the thoughts of Louv (2008, 156159). Authentic learning environments also coincide with the thoughts of Dewey (1938/1997). He sees the need for education to have a purpose that is meaningful for pupils in the present and that school should not be separate from society but a place where pupils learn by living. Education and how it is managed is important, as the cultural models that are formed in school are reflected on the surrounding society (Bruner, 1996). Opinions, actions and attitudes are more efficiently learned by experience-based learning than by formal education (Ballantyne \& Packer, 2009), which is why an authentic on farm learning environment might offer a valuable tool for education.

The term authenticity can be understood in different ways, why we want to define it before we go further. Authentic originates from Greek authentikós, meaning original, genuine or principal (Merriam-Webster, 2012). An authentic environment is therefore an environment that is truthful to its origins; it is not made up, developed or invented to fulfil a secondary purpose. For example, the farm is a place for primary production, agriculture, has its own culture and traditions and is the home of the farmer and his or her family. This is the truthful origin of a farm and its principal purpose. A farm that keeps farm animals for show is merely a zoo, as it lacks an element of truthful origin, primary production, and therefore fulfils a secondary purpose as a zoo. The actors and activities in an authentic environment should be underlined by dedication, sincerity, devotion and purpose for their work; farmers are not teaching or giving lectures, but proudly and honestly showing their work and allowing pupils to experience a part of it. An activity typical for the profession in a distinctive work place or surrounding is an essential part of an authentic environment. Participating in these activities is an important part in learning and understanding, experiencing, the environment and its purpose.

A learning environment refers to an existing setting that is intentionally used for teaching and learning purposes. A pupil's individual learning environment also includes intra- and interpersonal elements. The NCC (2004) defines learning environments as follows:

A learning environment is an environment where studying and learning takes place and that consists of a physical environment, psychological elements and social connections. The physical learning environment includes especially school buildings, learning equipment and materials, but also other built environments and surrounding nature. (p. 18)

Learning is a sensitive cognitive process that is affected by physical, psychological and social elements of the learning environment. This study will focus on the physical learning environment, not on the psychological elements and social connections of learning environments, as these are based on intraand interpersonal dynamics and not on concrete environmental factors. This study will not include virtual learning environments, although virtual learning environments are sometimes referred to as authentic learning environments. The reason is that in these cases authenticity refers to mimicking real life, not to its etymology as in this study. 
In our definition, an authentic learning environment combines the elements of authenticity and the requirements of a learning environment. In other words, an authentic learning environment offers pupils the possibility to learn about a subject in its genuine and original environment; if the subject to be taught is agriculture, then the lesson takes place on an active farm, where pupils are able to experience agriculture and the life of the farm and culture with all their senses (Smeds et al., 2011).

\section{Methodology}

The material for this study was gathered in April and May 2010. The participants were from four urban schools from the same town in western Finland. The methods used are subject-produced drawings and interviews. Data collection was carried out in school during biology lessons before and after the farm visit. A total of 102 drawings were received for study. The elements in the drawings are considered to be of symbolic value and telling a story, rather than an accurate representation of a farm.

\section{The farm visit}

The farm the pupils visited was situated $5 \mathrm{~km}$ from the pupils' school. The farm was of an average size conventional dairy farm with about 100 cows, heifers and calves in a free stall barn. The visit lasted for two hours and the pupils were allowed to participate in the feeding and caretaking of the cows as well as learn about what they eat, conventional and ecological farming, biodiversity, history, a cow's yearly cycle, about farm life, ethics and animal wellbeing, but also about economical issues in dairy farming.

\section{Subject-produced drawings}

Before and after the farm visit, the pupils were asked to draw what they expected a Finnish farm to be like. They were asked to draw freely on an A4 blank paper, without guiding, hints or talking to other pupils, what they expected to find on a farm. By this, we wanted to get the pupils' personal and genuine image of their conception. The pupils were not asked to draw a farmer, as this could have cultivated stereotypical images connected with the concept, which has been a criticism against the Draw a scientist test (DAST) (Boylan et al., 1992). Regardless of this criticism, DAST has proved to good method for measuring children's conception of scientists, as it does not demand writing skills and is not fixed or guided by direct questions as in questionnaires (Fung, 2002). Visual content analysis (VCA) as a procedure has been widely used especially in media studies (Bock et. al., 2011), but also in analyses of children's drawings (Ganesh, 2011). Strengths of content analysis include that it is a highly standardized method, if correctly completed, provides intersubjective replicable and valid results and reduces the visual material to a number of codes, which can be counted and statistically analysed (Bock et al., 2011). Children's drawings have been of interest since the end of the $19^{\text {th }}$ century. Barnes (1892, cited in Ganesh,
2011) concluded in his study that drawing pictures is the same as writing for young children, a way to convey an idea.

Flick (1990) has successfully used subject-produced drawings for pre- and post-assessment to measure the impact of an intervention. Drawings have also been used to examine attitudes and knowledge (Knight \& Cunningham, 2004), and conceptions and misconceptions of engineers (Ganesh, 2011). According to Ganesh (2011), drawings may serve as useful descriptive and analytical tools, if they are used carefully and rigorously. He further states:

As a descriptive tool, subject-produced drawings can be used to elicit individuals' understanding of a specific idea or construct. (p. 237)

In this study, drawings were analysed by visual content analysis (e.g. Bock et al., 2011; Ganesh, 2011; Rose, 2007). The procedure consisted of coding the elements in the drawings. Elements in drawings were regarded as symbols and not as accurate representations. Codes need to be robust, meaning that codes are explicit to an element and not overlapping with another code. For example, if a pupil had drawn a cow, it would be coded 1.2.1.3 (1=Living, 2=Animals, 1=Farm, 3=Cow). Coded elements were further categorised and quantified. Validity of analysis was verified similarly to Smeds et al. (2011) by intercoding (match $93 \%$ ). The validity is increased by presenting drawings from the study to elucidate different elements.

Quantification of content analysis was made to determine frequencies of the categories, to see if there are any differences between girls and boys and how a farm visit affects different frequencies. Frequencies were statistically tested for significance by Pearson's chi-squared test (Ranta et al., 1991; Fung, 2002). Ranta et al. states that $20 \%$ expected frequencies need to be higher than 5 and every expected frequency at least 1.

\section{Interviews}

Interviews were carried out to arrive at a comprehensive image of what urban Finnish pupils think of agriculture and to find out what affected the pupils' attitudes most. Interviews have been recommended in earlier research to be used after the drawing activity to gain a better insight into pupils' reasoning (Boylan et al., 1992; Fung, 2002). Eight (11year-old) pupils were chosen for interviews. They were selected according to their interest in spending a school day on a farm, which was asked before and after the farm visit. The interviewees were chosen to represent unchanging, rising and dropping attitudes; positive-positive, neutral-neutral, negative-positive and positive-neutral and neutral-negative. The interviews were conducted at school on a school day one week after the farm visit by one of the researchers that carried out the intervention who was thus familiar to the pupil. The interviews were personal thematic semi-structured interviews that were recorded for 
analysis. The duration of an interview was 10-42 minutes depending on the pupil (median 16 minutes).

Inductive content analysis was chosen for analysis of the interview answers based on open questions, as it is sensitive to context, systematic, and objective (Graneheim \& Lundman, 2004; Tuomi \& Sarajärvi, 2004; Elo \& Kyngäs, 2008; Smeds et al., 2011). This analysis method is truthful to the collected material, as categorization is based on the themes that emerge from the pupils' writing. The analysis consists of three phases; preparation, organization and reporting (detailed procedure of analysis in Smeds et al., 2011). Reliability and validity in inductive content analysis are concurrent with other research methods. The validity of the research is increased by authentic citations by showing where from or from what kind of original data the categories are formulated (Patton, 1990).

\section{Results}

The results are presented in groups according to the data collection method.

\section{Drawings}

We first present the pupils' pre-conception of agriculture, and secondly their conception of the same phenomenon after the educational farm visit.

\section{Pre-assessment}

The elements will be represented by grouping names, not with codes, to keep this chapter more understandable. The grouping names were later used as names for the categories.

In Figure 1, the drawings are classified as rational and include ordinary living and non-living farm elements, such as farm animals (pig, chicken, cow, horse), plants (grain), buildings (barn), machinery (tractor) and farm equipment (pitch fork). Some animals were drawn to show positive emotions (Figure $1 \mathrm{~b}$ and $1 \mathrm{c}$ ). No farm activity or farmers can be seen in these drawings.

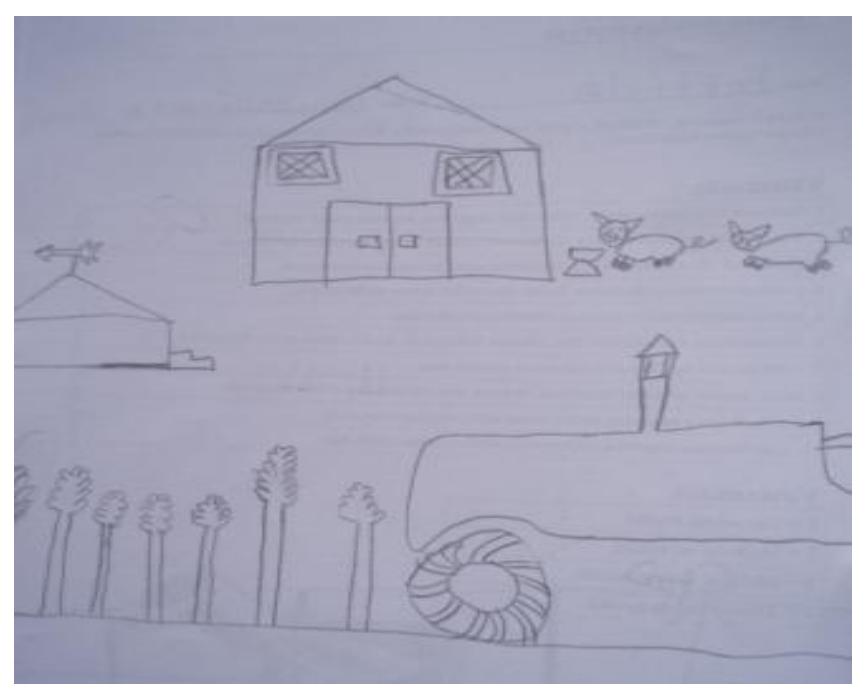

(a)

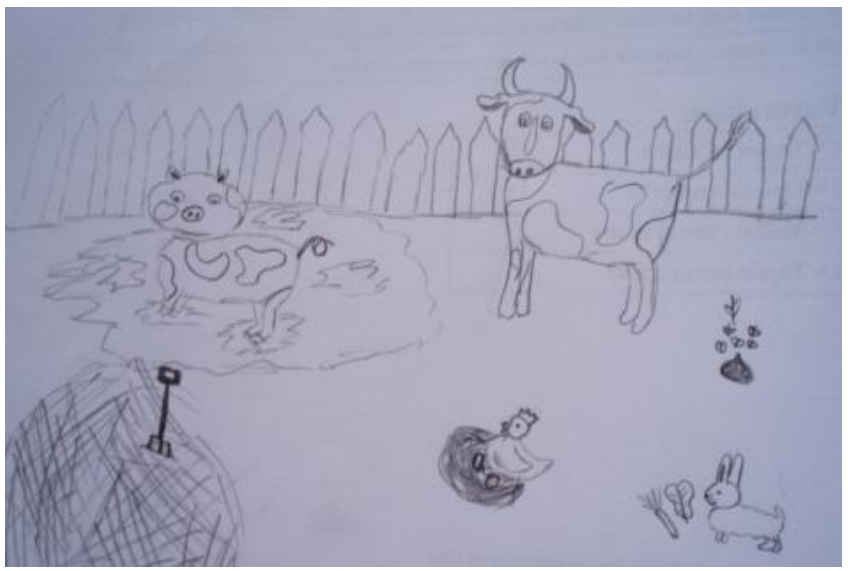

(b)

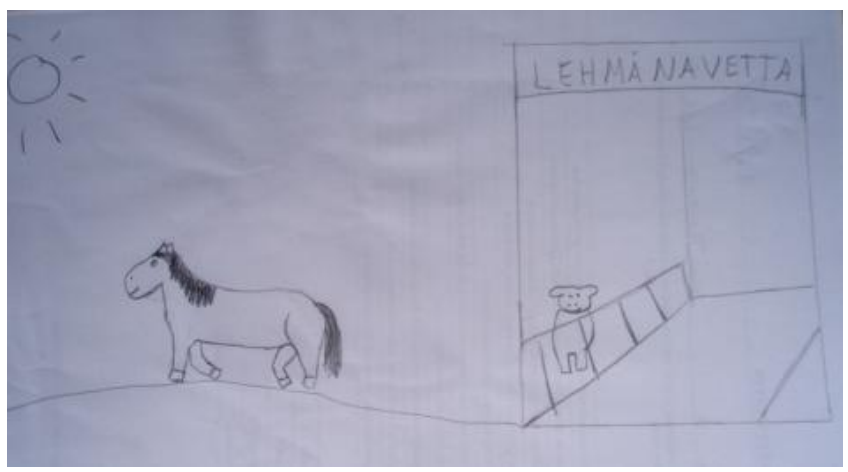

(c)

Figure 1, a-c . Ordinary living and non-living farm elements.

The drawings (Figure 1, a-c) are also considered rational, even though they include practical issues that do not occur on a farm. On an ordinary farm, pigs and horses do not roam freely (Figures 1, a-c), farm animals would not be kept in the same pen (Figure 1b), and a hen would not lay eggs in a nest in the middle of a pen (Figure $1 \mathrm{~b}$ ). These drawings tell a story of a harmonious life on the farm with many different farm animals that fodder close by and plenty of space to roam in. No farmers or other agriculture activity can be seen in these drawings.

In Figure 2, the drawings can be labelled as stereotypic farmers and were coded and categorised top to down as Living - People - Personalised - Peasant (see Figure 8). 


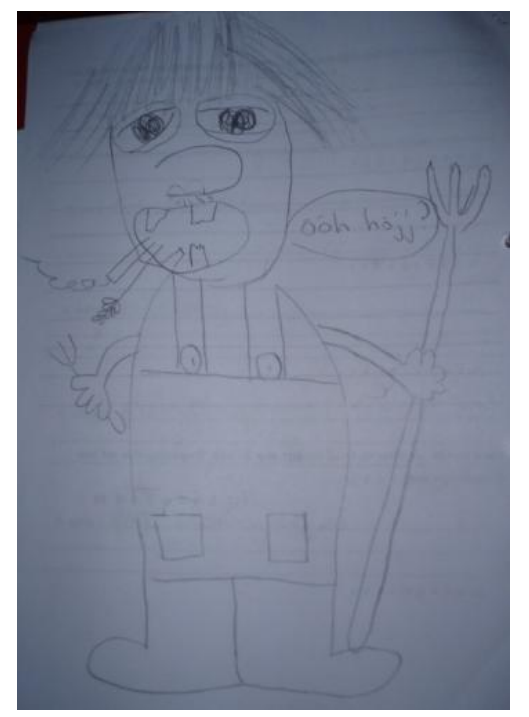

(a)

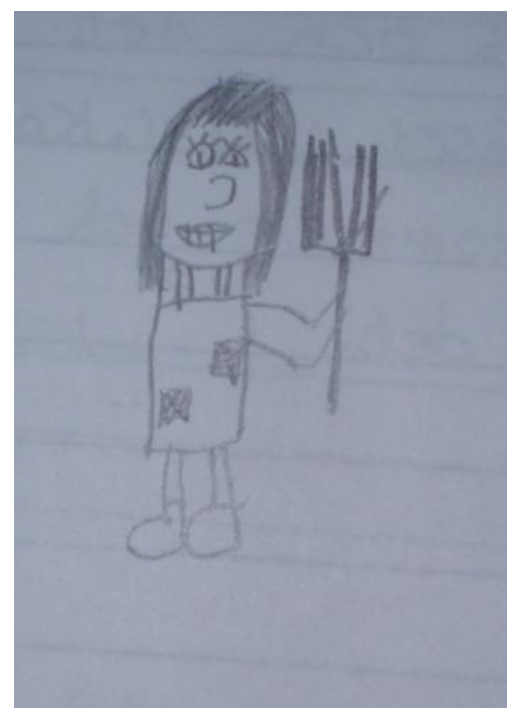

(b)

Figure 2, a and b. Unhealthy and poor farmers.

Elements in these drawings (Figure 2, a and b) tell a story that farmers are unhealthy (smoking and they have bad teeth in Figure 2a), ignorant or simple minded (comment in Figure 2a), are poor (bad teeth in Figure $2 \mathrm{a}$, clothing in Figure $2 \mathrm{~b}$ ) and mainly do manual and simple labour (pitchforks). No other aspects of farms or agriculture were present in these drawings. These caricatures were categorised as irrational, as no statistics claim that farmers are less healthy, well-off or intelligent than the rest of the Finnish population.

In Figure 3 (a and b), an exotic animal is drawn together with a farm animal, here an elephant together with a horse (Figure 3a) and a hippopotamus (Figure 3b). Elephants (Figure 3a) and hippos (Figure 3b) can only be seen in Finland in zoos specializing in exotic animals, not on farms. The pupil that drew Figure $3 \mathrm{~b}$ even wrote the word "hippopotamus" next to the animal. These were therefore categorised as irrational elements and as exotic animals. No specific agriculture activity, farms or farmer can be seen in these drawings.

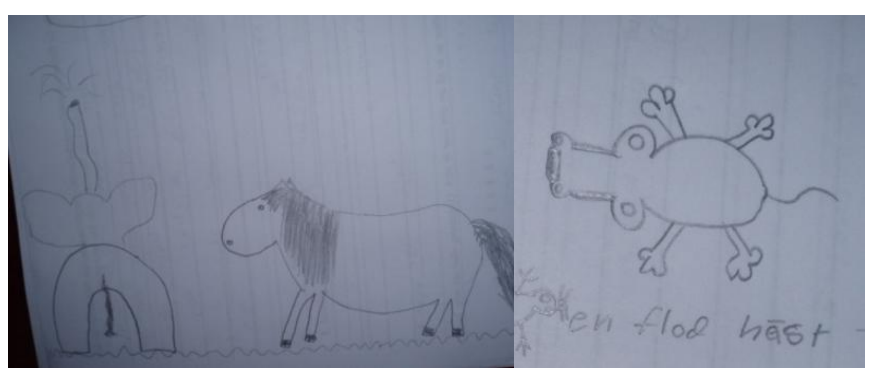

(a)

(b)

Figure 3, a and b. Exotic animals together with a farm animal.

Fantasy animals can be found in sci-fi or fantasy games, films or books, but not in a live Finnish farm (Figure 4). These were categorised as irrational and top-down as Living - Animals - Fantasy animals (see Figure 8). No farm-related elements were present.

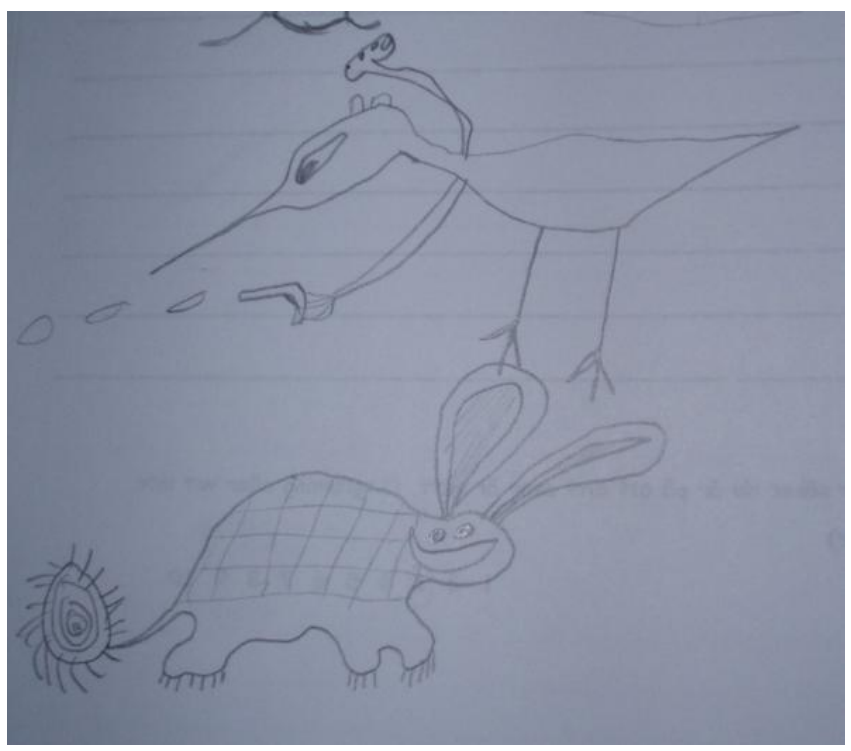

Figure 4. Unidentifiable fantasy animals.

Animals, here pigs, with human features (Figure 5) are fantasy animals, but due to their distinct human characteristics they were placed in their own category, Humanified (see Figure 8). No other farm related elements were present in this irrational drawing.

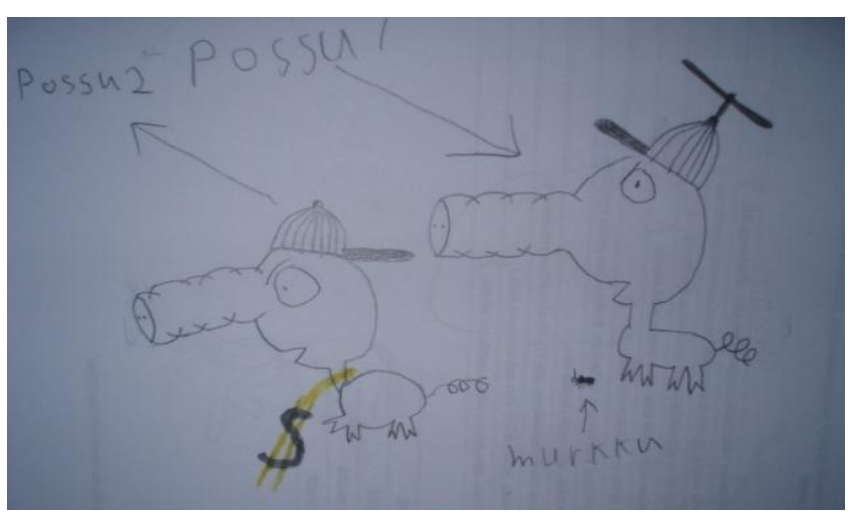

Figure 5. Humanified farm animals. 
The drawing below (Figure 6) represents another category of irrational drawings, Fantasy tractor. The tractor is a combination of a cow and a tractor, but has also anarchistic and patriotic features as signs and writing on the side. A cat can be seen driving the tractor to a fodder machine.

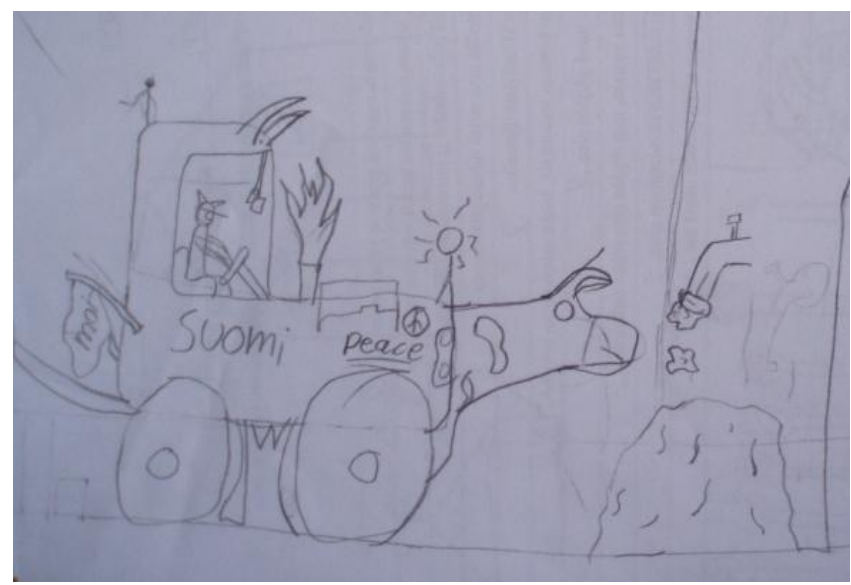

Figure 6. A drawing with a fantasy tractor driven by a cat.

Emotions, positive or negative, have in this analysis been identified by the drawn face features on people and animals. Drawings tell a story, and clear elements of emotion represent symbols of how the pupils portray their attitudes towards agriculture in general. In Figure 7, elements of negative emotions can be identified by wrinkles on the forehead and slanting eyebrows. General mood of a drawing and neutral emotions have not been categorised.

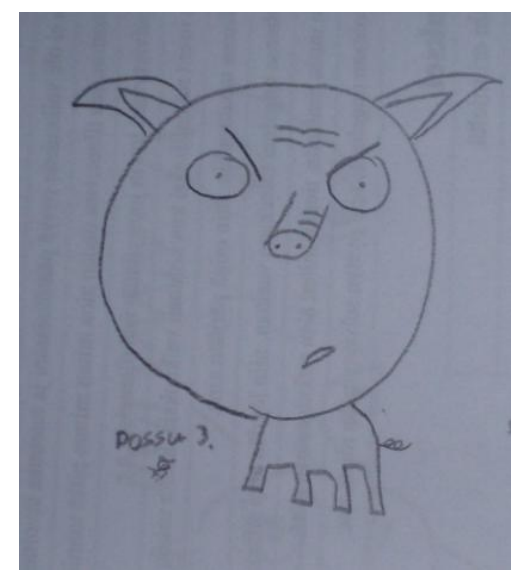

Figure 7. Drawing showing negative (aggressive) emotions on a farm animal.

The results of visual content analysis reveal four main categories; Living, Non-Living, Activity, and Emotion
(Figure 8). The main category "Living" includes categories People, Animals and Plants, according to the found elements. People were further subcategorised as Stick figures or as Personalised ones with bodies and other personal features. The animals include subcategories such as Farm, Exotic, Fantasy and Humanified. The plants include subcategories Grass that also includes grain and other detailed plants, and Scenery, plants in general at a distance. "Non-living" includes the categories Machinery and Buildings. Machinery is represented by the subcategories Tractors and Fantasy tractors, and Buildings by Barns. "Activity" includes the category Farm work, which can be divided into subcategories Driving a tractor and Manual that includes farm work done by human labour. "Emotions" include the categories Positive and Negative, where positive features were found on either people or animals and were subcategorised based on it. The negative elements were mainly subcategorised as Aggressive. In general, the drawings were neutral or positive, included animals and showed an optimistic image of farms and agriculture. All the main categories included irrationalities before the farm visit.

The quantification of visual content analysis showed that the most common thing that pupils expected to see on a farm was an animal (83\%), especially a farm animal such as a pig (37 \%) (Table 1.). But exotic (8\%), fantasy (6\%) and humanified animals (13\%) were also drawn, and especially the boys drew fantasy (12 $\%)$ and humanified animals (23 \%). People were present in $33 \%$ of the drawings (girls $23 \%$, boys 42 $\%) .19 \%$ of these drawings were personalised, implying that the image was more than a plain stick figure. Especially the boys $(23 \%)$ did this personalisation indicating that the drawing was a caricature of a farmer and grouped as "peasant". Plants were drawn especially by girls $(27 \%)$ rather than boys (8\%), and machinery, tractors by boys (23\%) compared to girls (4\%). Farm work was drawn by 15 $\%$ of the pupils. Emotions were identified by facial expressions on either drawn people or animals. Drawings with positive expressions were found in 50 $\%$ of girls' drawings and $31 \%$ of boys' drawings. Girls had drawn more animals with positive expressions (35 $\%)$ than boys (12\%), whereas boys had drawn more people with positive expressions (19\%) than girls (15 $\%)$. No negative expressions could be identified in the girls' drawings but in $12 \%$ of the boys' drawings. 


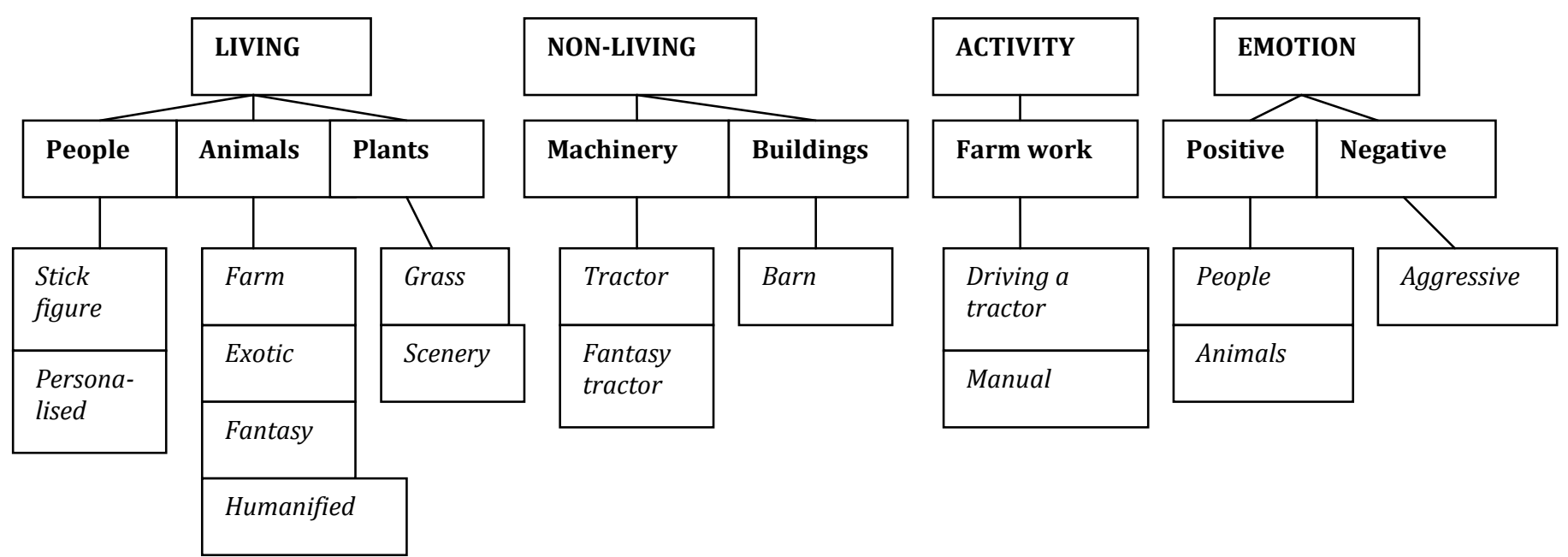

Figure 8. Results of quantified visual content analysis of the pre-assessments ( 26 girls, 26 boys). The main category in capital letters, category in bold and subcategory in italics.

Table 1. Quantification of pre-assessment visual content analysis (in per cent) (26 girls, 26 boys).

\begin{tabular}{l|lll} 
& Total \% & Girls \% & Boys \% \\
\hline Living & \multicolumn{3}{l}{} \\
\hline People & $\mathbf{3 3}$ & $\mathbf{2 3}$ & $\mathbf{4 2}$ \\
Stick figure & 13 & 8 & 19 \\
Personalised & 19 & 15 & 23 \\
*Peasant & 13 & 4 & 23 \\
Animals & $\mathbf{8 3}$ & $\mathbf{8 5}$ & $\mathbf{8 1}$ \\
Farm & 65 & 81 & 50 \\
*Pig & 37 & 38 & 35 \\
*Chicken & 13 & 4 & 23 \\
$*$ Cow & 19 & 23 & 15 \\
$*$ Horse & 21 & $35 *$ & $8 *$ \\
Exotic & 8 & 8 & 8 \\
Fantasy & 6 & 0 & 12 \\
Humanified & 13 & 4 & 23 \\
Plants & $\mathbf{1 7}$ & $\mathbf{2 7}$ & $\mathbf{8}$ \\
Grass & 12 & 19 & 4 \\
Scenery & 6 & 8 & 4 \\
\hline
\end{tabular}

\begin{tabular}{|c|c|c|c|}
\hline \multicolumn{4}{|l|}{ Non-living } \\
\hline Machinery & 13 & 4 & 23 \\
\hline Tractor & 10 & 4 & 15 \\
\hline Fantasy tractor & 4 & 0 & 8 \\
\hline Buildings (barn) & 8 & 8 & 8 \\
\hline \multicolumn{4}{|l|}{ Activity } \\
\hline Farm work & 15 & 12 & 19 \\
\hline Driving tractor & 12 & 4 & 19 \\
\hline Manual & 4 & 8 & 0 \\
\hline \multicolumn{4}{|l|}{ Emotions } \\
\hline Positive & 40 & 50 & 31 \\
\hline Humans & 17 & 15 & 19 \\
\hline Animals & 23 & 35 & 12 \\
\hline $\begin{array}{l}\text { Negative } \\
\text { (aggressive) }\end{array}$ & 6 & $\mathbf{0}$ & 12 \\
\hline Irrational elements & 38 & $15 *$ & $62 *$ \\
\hline
\end{tabular}

Note that the percentages indicate occurrence of specific elements in drawings and several categories and subcategories might be present in the same drawing. Statistical significance in Chi-square test is indicated by * $(\mathrm{p}<0.05)$.

\section{Post-assessment}

The drawings were analysed by visual content analysis according to the same principles as in pre-assessment. Many of the pre-assessment categories were still present in post-assessment, but new ones also emerged. One of these new categories is Experiencing, as represented in Figure 9.

As irrational elements were present in all the main categories, they were not categorised in particular. They were taken into account in the quantification, and irrational elements were found in a total of $38 \%$ of all the drawings; significantly more in the boys' drawings $(p<0.05)$. Elements that were defined as irrational were elements that cannot be found on a typical Finnish farm, e.g. exotic, fantasy or humanified animals, caricature peasants or fantasy tractors (Figures 2-6).

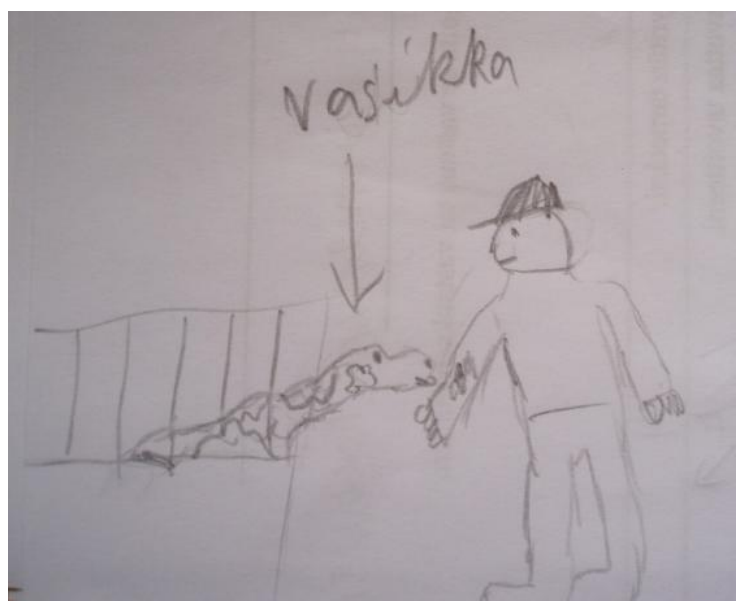

Figure 9. A calf licking a boy’s shirt. 
It is typical of this category that the pupil has drawn him- or herself experiencing something on the farm. This category does not involve any clear activity, but rather an experience by different senses.

The pupils' drawings became more rational and detailed in the post-assessment. In Figure 10, the inside of the barn building was drawn in great detail including objects (pitchfork, wheelbarrow) that the pupils had used to feed the cows. The drawing shows the result of a pupil's activity; a cow eating fodder administered by thepupil.

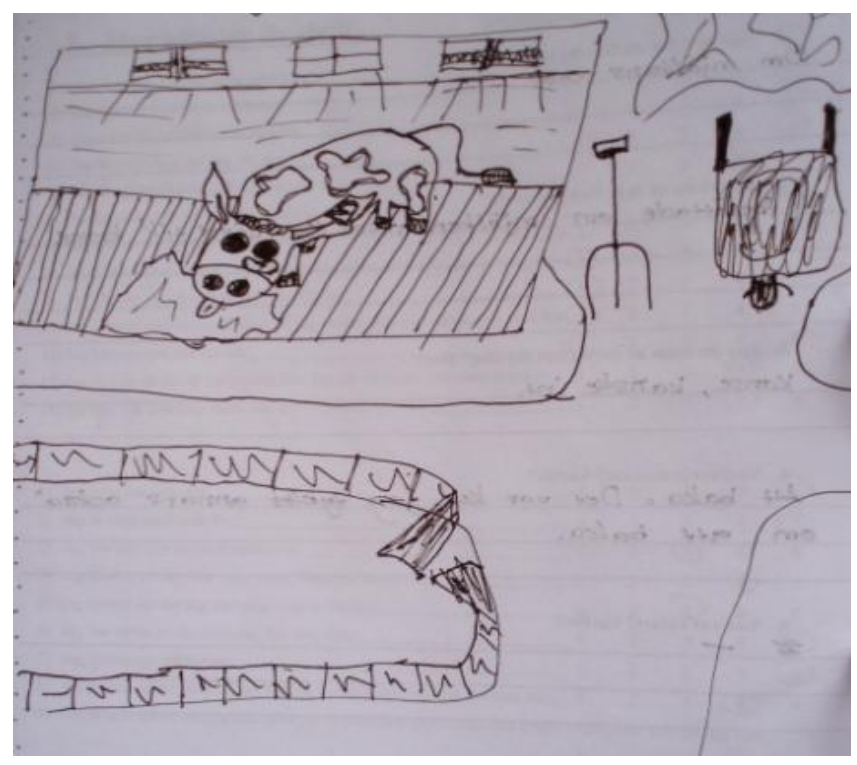

Figure 10. Drawing with barn building and cow.

The drawing (Figure 11) shows a pupil taking fodder from a bale and feeding a cow. The Farm work in this drawing was further categorised as Personal activity, due to the pupil's written explanation (not shown in the drawing). Without this explanation it could also have represented Social activity. Other categories identified in this drawing are Positive (subcategorised as People), in main category Emotion, and subcategories Stick figure and Farm animal (Table 2).

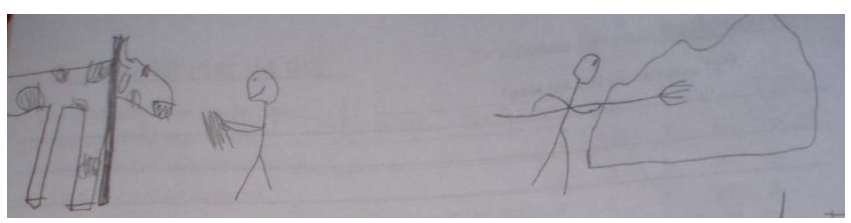

Figure 11. Drawing of a pupil feeding a cow.

In general, post-assessment drawings were more detailed and realistic, compared to pre-assessment drawings. Irrational elements were almost absent and various sorts of farm activities could be seen more frequently.

The results of visual content analysis reveal the same four main categories; Living, Non-Living, Activity, and Emotions (Figure 12) as in pre-assessment. The main category "Living" has lost two subcategories, Exotic and Fantasy, in the Animals category. This result shows that the number of irrational elements has decreased. The main category "Non-living" has also lost the subcategory of Fantasy tractor and is therefore a completely rational main category. The main category "Activity" has gained four new subcategories; Social activity, Personal activity, Product of activity and Experiencing, and lost one, Manual. The main category "Emotion" has lost subcategory Aggressive, and gained Scared.

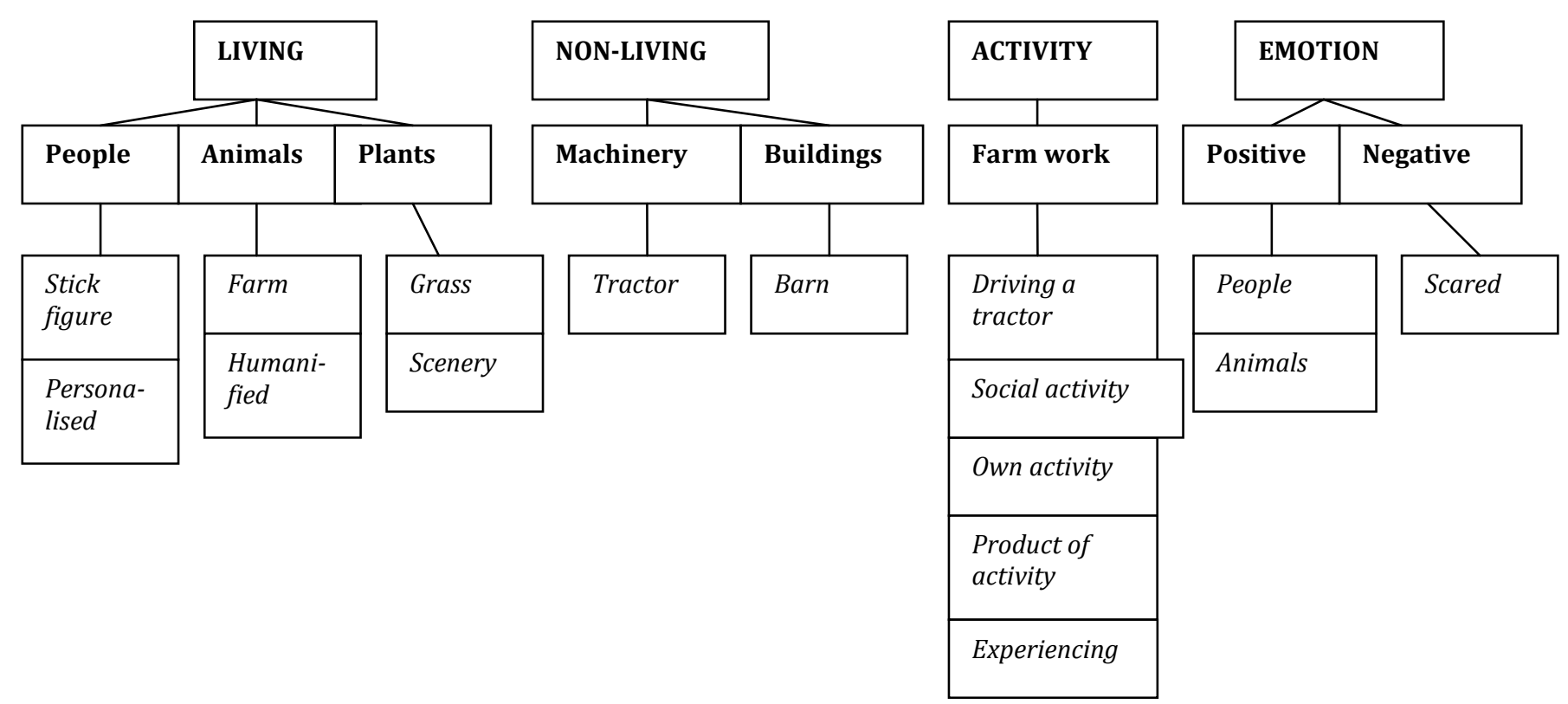

Figure 12. Results of the quantified visual content analysis of post-assessment (27 girls, 23 boys). Main categories in capital letters, categories in bold and subcategories in italics. 
In general, the greatest difference between pre- and post-assessment is the fact that there are fewer subcategories with irrational elements and an increase in different farm activities, especially ones carried out by the pupils by themselves or together with fellow pupils.

The quantification of pupils' experiences showed that the total number of irrational elements had significantly decreased from $38 \%$ to $4 \%(p<0.0005)$, and among boys from $62 \%$ to $9 \%(p<0.005)$ (Table $2)$. Different farm activities had significantly risen from $15 \%$ to $36 \%(p<0.05)$. Activities on farms were pictured in $36 \%$ of drawings, showing especially the pupils' own agriculture activities (28\%), working together $(12 \%)$ and experiencing something memorable (16\%). The people drawn by the pupils (34\%) were stick figures (34\%) or personalised (20 $\%)$ with no caricature features. Especially the boys (52 $\%)$ were keen to draw people compared to the girls (19 $\%)$. Animals were drawn by $64 \%$ of the pupils. These were only farm animals, and irrational humanified caricatures were found in $4 \%$ of drawings. Plants were pictured in $14 \%$ of drawings. Non-living items such as tractors (14\%) and barns (18\%) were drawn by the pupils, but with no fantasy aspects.

Table 2. Quantification of post-assessment visual content analysis (in per cent) (27 girls, 23 boys).

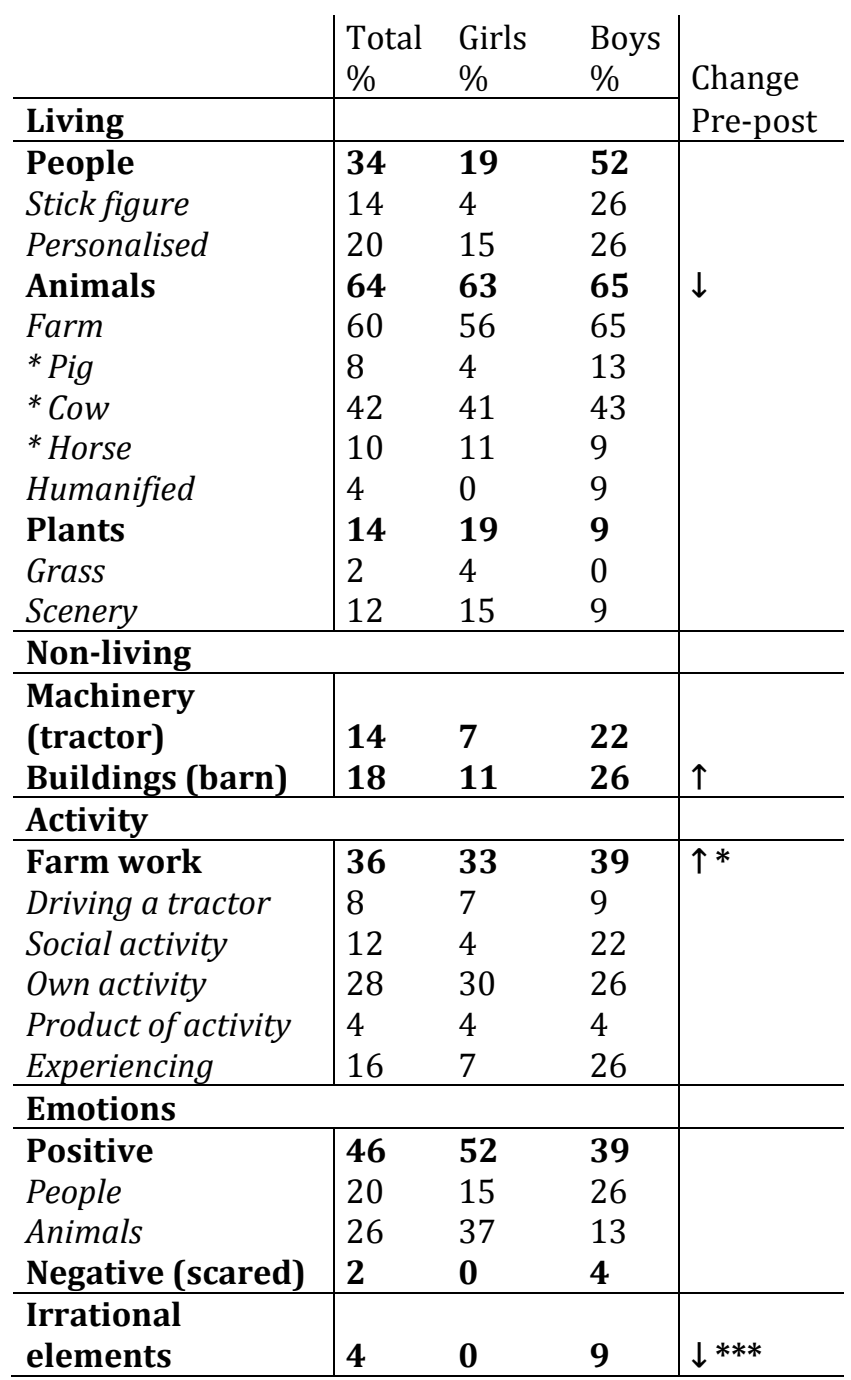

Arrows $(\uparrow, \downarrow)$ indicate a change $>10 \%$ in categories between pre- and post-assessment and star $(*)$ indicates changes that are statistically significant by Pearson's Chi-square test $\left({ }^{*} \mathrm{p}<0.05,{ }^{* * *} \mathrm{p}<0.0005\right)$.

The emotions that could be identified in the drawings were $46 \%$ positive and $2 \%$ negative (scared). The girls had drawn more positive emotions on animals, and the boys on people.

\section{Interviews}

Interviews were conducted to gain deeper information about the effects of the interventions and to get a more comprehensive picture of the pupils' conception of agriculture. The results were ordered according to this grouping. The pupils' comments will be referred to by numbers 1 to 8 , not by gender, as this could risk their anonymity in such a small sample. Authentic quotes by the pupils are used to strengthen the validity of the research.

None of the interviewees had a relative or a friend on a farm. Four pupils had visited a farm or a tourist farm once with their pre-school group or with parents when they were younger. Two had never visited a farm and two had visited one a few times. There was no connection between interest and the number of earlier farm visits.

The two pupils who had positive feelings towards farm visits, before and after the visit, felt that their expectations for the farm visit were met. They both pointed out that they liked the fact that they could study the topic in its authentic environment and also liked the outdoor life. One of the pupils commented that the conception did not change, but they learnt more than in the classroom. One of the pupils criticized media for false impressions of cows. Nonetheless, such experiences did not affect negatively on the pupils' overall positive experience of the visit or towards farms.

"Well, for instance the cows, in advertisements the cows are tidy and when you went there, they were dirty." (Pupil 1)

Two of the pupils were neutral to towards a farm visit. Their earlier experiences had some negative aspects that affected these pupils attitude.

"I have been there, it was fun to start with, but then there were some problems." (Pupil 3)

"Animals are nice and it was fun to work there. The only downside was the smell." (Pupil 4)

When these pupils were asked about how they felt when they were told about the farm visit, none of them were quite exited. One of them would have preferred to go somewhere else When the pupils were asked to explain if their conception of farms and agriculture had changed, one of the pupils thought that the conception had changed, not for better or worse, but it had changed as a result of new knowledge and understanding. Especially the fact that farms are modern enterprises with advanced technology and not 
old fashioned replicas from past days was new knowledge to one pupil.

"I have always thought that a farm is a kind of shed and that there are some sort of animals.... but there was more of such modern technologies." (Pupil 3)

The pupil also referred to the media for requiring knowledge, when responding to comments on how he thought farmers were clothed (overalls, Wellingtons) and their not having working phones. He admitted that the media had a major impact on his conception of agriculture.

“...I don't believe everything that the programs say, but a little." (Pupil 3)

The pupil conception was that a farm is an unchanging and static environment, close to a museum, even though they were able to take part in farm work (feeding cattle).

"Once you have seen the machinery, it's kind of great, and the second time you come and see it, it is still ok, but the third time you think you've already seen it twice." (Pupil 3)

Two of the pupils were negative towards a farm visit. One of the pupils would have wanted to milk a cow, but when informed that milking a cow by hand was not possible on a modern farm, the pupil commented negatively on the pre-assessment. One pupil that had never visited a farm was negative without a specific reason. The pupils tried to explain why their attitudes towards farms and agriculture had drastically changed from negative to positive. They could not really specify, but they thought it was fun there. One of the pupils (Pupil 5) explained that the conception of farms and agriculture is the same, but better, without being able to describe more closely.

Two pupils were not interested in another visit. The pupils were afraid it would be boring or smelly on the farm, but would participate again, if there was something new to learn about it.

"It would be nice to go to the farm and see animals and learn something new about them, but we have already been there and seen almost everything." (Pupil 7)

"When I thought about a farm before, I thought it stinks terrible there and that it is a small place with not many animals... but it was fun." (Pupil 8)

When they were asked to compare their general opinion about farms before and after the visit, they both thought that it had changed for better. Previously, they had mainly thought of farm animals (cows, pigs) when thinking about farms, but now they explained that they had a completely different image. They were not able to tell how but they also referred to gained knowledge.

\section{Interviews in conclusion}

There was no connection between the number of earlier farm visits and the pupils' interest in participating in an educational farm visit. The effect of the media was mentioned as a source of information on agriculture that also had an impact on the pupils' attitudes. An expected negative experience on the farm or actual earlier experience also affected the pupils' interest in farm visits. Experience and gained knowledge gave the pupils a more comprehensive and positive image and understanding of agriculture, but did not affect their general interest in another farm visit. A general concern for many pupils was the fact that they gathered that a farm is a static environment, where they would not be able to learn anything new or gain new experience once they had been there. The visit and experience itself might have been interesting and fun, but they did not experience farms as a dynamic environment where every season offers a new aspect of learning.

\section{Discussion}

Our post-modern society is full of splintered knowledge that pupils have to understand and use for sustainable choices and conscious decisions about their future. Without understanding how these pieces of knowledge interact and form our reality, sustainable choices will be hard to make. Authentic learning environments allow pupils to study the whole subject (a farm), after which the pieces of knowledge interact and form this complex image (farmer, agriculture activities, history, animals, ecology). In an authentic environment the pupils are able to study the way in which every action, or absence of action, has a consequence. . The drawings revealed that $38 \%$ of pupils have an image and conception of agriculture that includes irrational elements that are not part of Finnish farms, farmers or agriculture. The elements classified as irrational, such as caricature farmers, humanified animals and fantasy machinery, are typical characters in many popular and well-known children's shows and cartoons set in a farm environment (e.g. Bob the builder or Donald Duck). In some Finnish and Swedish (Stenbacka, 2011) anecdotes and children's programmes (e.g. Hölmöläiset, Herra Heinähattu), farmers are described as slow witted, funny and poor. As many pupils lack personal experience of farms and farm environments, they have to build their mental schema on the information they acquire from sources (e.g. television, movies, comic books) in their surroundings (Gardner, 1980; Palmer, 1998). The pupils' reality of agriculture thus seems to be blended with fiction. The teacher's role is therefore important. He or she should be aware that pupils might possess mental schemes that do not coincide perfectly with reality and that their conceptions might include irrationalities. These conceptual irrationalities can best be cleared in confrontation (Vosniadou, 1994). The participating pupils had studied agriculture in the school term before these interventions, but an excessive amount of irrationalities was still present. This suggests that in many cases their knowledge had been acquired and put together with elements gathered from the surrounding sources. This is 
possible, as pupils use several sources to gather information (Gardner, 1980).

Exotic animals do not belong to a Finnish snow climate, but to zoos and countries with equatorial and warm climates. The pupils who drew exotic animals might have gathered that farms are like zoos that you are able to visit and look at the animals or they might themselves be from a country where these animals in fact are farm animals. The pupils' ethnic origin was not checked when the background information was gathered, why a culture in a more southern climate could be a possible explanation.

In the interviews the pupils indicated that their conception of agriculture had mainly changed due to gained knowledge. Learning activities in an authentic learning environment allowed the pupils to be involved in creating and experiencing knowledge in its real environment and by this promoting a more comprehensive conception and understanding of the phenomenon to be learnt. This result clearly illustrates the importance of personal experience (Ballantyne \& Packer, 2009) in the learning process and in shaping the pupils' mental schemata as well as authentic learning environments. These findings are also supported by the thoughts of Dewey (1938/1997), who maintains that pupils' learning must be linked to their surroundings and be purposeful and meaningful in the present.

The pupils' conception of agriculture was significantly more realistic after the farm visit, as total amount of irrational elements in pupils' drawings had decreased from $38 \%$ to $4 \%$. The farm, as an authentic learning environment, was able to significantly reduce elements in pupils' drawings that cannot be found on a Finnish farm. This was confirmed by the pupils' comments in the interviews. They referred to the media (e.g. advertisements) when explaining where their false conceptions had originated, such as clean cows when they actually had some dirt on them. A romantic image of simple traditional agriculture was also expected without any advanced form of technology, such as mobile phones. This corresponds with earlier studies by Smeds et al. (2011), where especially urban pupils showed a tendency to combine romantic associations with farms and agriculture that are typical Finnish cultural countryside values. Traditional agriculture may also be found in the media (e.g. television series, comic books, food advertisements), where it represents agriculture. This fosters false traditionalism, as cows are not milked by hand, but by milking robots, and farms do not mainly use human labour but advanced machinery for most farm activities. This is supported by the findings of Stenbacka (2011). One pupil commented in the interview that he did not believe everything that he saw on television, but some of it. The importance of education is underlined; the pupils need a solid basis on which to build their knowledge of agriculture, so they are able to realise that they have encountered irrational or false information and are able to decide not to attach it to their mental schema. The inclusion of authentic learning environments in education could promote building of such solid bases for learning, as they have proven in his study to reduce significantly irrational elements in the pupils' conceptions.

The pupils' drawings after the farm visit illustrated significantly more activity (farm work) than before the visit. The pupils' portrayed themselves as farmers carrying out activities and presenting their results. Ganesh (2011) has found a similar phenomenon in her research. The pupils also highlighted working together with fellow pupils (social activity) and experiencing different farm specific phenomena. Even though the pupils thought that the visit and experience had taught them a lot, they did not experience farms as a dynamic learning environment. Agriculture and farms are quite dynamic as the work itself and the farmer have to interact with weather, the seasons and the environment, as well as with the life cycle of any farm animals. The pupils rather thought that farms were static and unchanging environments and that they had learnt everything about them during one or two visits. There are some possible explanations for this conception. The first explanation is that the pupils visited their farms once. In other words, they got one glimpse of one season and one stage in the farm animals' life. They were lectured about seasonal work on the farm, they saw the machinery and farm animals in different life cycles, but they did not experience the change between different stages. They were only taught about them, similarly to education in a classroom. Another explanation might be that the pupils felt that their activities belonged to them, and not to the farm. The pupils did not see any agriculture activity, they were doing agriculture activities. They might have thought that when they went home, the activities did not continue on the farm. The farmer spent his time guiding the pupils in their tasks and demonstrating life on the farm instead of doing agriculture tasks. The pupils could have got the impression that the farm is a static place where the farmer is walking around and guiding pupils. It might be that the farmer should have taken a greater part in the work for the pupils to gain a more dynamic image of agriculture. Further research will be needed to clarify why farms were seen as static environments.

\section{Validity and Reliability of the Research}

The use of two different methods, drawings and interviews, allowed us to gain a better insight into the pupils' conceptions of agriculture. The drawings provided information about the diversity and frequency of the conceptions, while the interviews gave a deeper insight into the experience that modified these conceptions. This enhanced the validity of the research, as one method completed the other. The same researchers took part in the interventions, in the collection of the data materials as well as in the analysis, which increased validity as the researchers 
are familiar with the activities and the environment of the interventions and can result in a better insight into the researched phenomenon. The drawings as a research method could have given deeper answers and explanations in this study, if the pupils had been asked to write about their drawings and what happened in them. Drawings have been criticised for producing stereotypical results (Fung, 2002), which is why it is good to combine drawings with an explanatory method, such as interviews, to clarify the results of the phenomenon. Although measures were taken to make the interview situation as natural as possible for the pupils (the interview was carried out in school during the school day and the pupils were familiar with the researcher based on the interventions), the results should still be interpreted with caution. Some of the pupils were quite reserved when interviewed, which might have affected their reflection on the farm experience, as reflection is a process that is not easy to accomplish. An additional method to drawings that has been used in some research is working groups and brainstorming with fellow pupils (McCormack, 2002). This method was not chosen, as it would not capture individual thoughts.

\section{Conclusion}

There are four main conclusions to be made based on this material. First of all, children's conception of agriculture does differ from reality, even though they have studied the subject in school. Their conception includes several irrational elements that might be traced to media sources. Secondly, authentic learning environments proved to be valuable places of learning. These learning environments confront pupils' schemas of the environment and allow them to test their schemas through experience for any irrational elements gained from the media, for instance. This should be taken into account in teacher education, curricular work and school practises. Thirdly, if children grow up believing that agriculture is a profession of lesser importance, it will not encourage them to get an education in agriculture and rural areas will suffer from a loss of qualified employees. Fourthly, if children's conception, opinions and values of agriculture is based on information blended with fiction, they will not be able to make truthful choices regarding food. They will not be able to correctly understand how their decisions affect their health, society, the environment, their culture or agriculture in a larger perspective, now or in the future.

\section{References}

Ahonen, S. (2003). Yhteinen koulu. Tasa-arvoa vai tasapäisyyttä? Vastapaino, Tampere.

Ballantyne, R., \& Packer, J. (2009). Introducing a fifth pedagogy: experience-based strategies for facilitating learning in natural environments. Environmental Education Research, 15, 243-262.

Bandura, A. (1997). Self-efficacy: The exercise of control. New York: W.H. Freeman and Company.
Bock, A., Isermann, H. \& Knieper, T. (2011). Quantitative Content Analysis of the Visual. In: Margoilis, E. and Pauwels, L., Editors, 2011. The SAGE Handbook of Visual Research Methods, SAGE Publications Ltd.

Boylan, C.R., Hill, D.M., Wallace, A.R. \& Wheeler, A.E. (1992). Beyond stereotypes. Science Education, 76, 465-476.

Bruner, J. (1996). The Culture of education. Cambridge, Massachusetts, London: Harvard University Press.

Dahlgren, L.O. \& Szczepanski, A. (1997). Utomhuspedagogik - Boklig bildning och sinnlig erfarenhet. Skapande vetande 31. Linköping: Linköpings Universitet.

Dewey, J. (1938/1997). Experience and education. New York: Macmillan.

Elo, S. \& Kyngäs, H. (2008). The qualitative content analysis process. Journal of Advanced Nurs-ing, 62, 107-115.

Flick, L. (1990). Scientists in residence program improving children's image of science and scientists. School Science and Mathematics, 90, 204214.

Fung, Y.Y.H. (2002). A comparative study of primary and secondary school students' images of scientists. Research in Science and Technological Education, 20, 199-213.

Ganesh, T.G. (2011). Children-Produced Drawings: An Interpretive and Analytical Tool for Researchers. In: Margoilis, E. and Pauwels, L., Editors, 2011. The SAGE Handbook of Visual Research Methods, SAGE Publications Ltd.

Gardner, H. (1980). Artful scribbles. New York: Bavi Books.

Graneheim, U.H. \& Lundman, B. (2004). Qualitative content analysis in nursing research: concepts, procedures and measures to achieve trustworthiness. Nurse Education Today, 24, 105112.

Knight, M. \& Cunningham, C. (2004). Draw an engineer test (DAET): Development of a tool to investigate students' ideas about engineers and engineering. Paper presented at the American Society for Engineering Education, Salt Lake City, USA.

Louv, R. (2008). Last child in the woods. Saving our children from nature-deficit disorder. New York: Workman Publishing Company.

Maatilatilastollinen Vuosikirja (2011). (The Yearbook of Farm Statistics) Tike. Matilda, maataloustilastopalvelu. Retrieved 27.02.12, from: http://www.maataloustilastot.fi/maatilatilastolline n-vuosikirja-2011_fi.

Mabie, R. \& Baker, M. (1994). Strategies for improving agricultural literacy and science process skills of 
urban fifth and sixth graders in the Los Angeles unified school district. Paper presented at the Annual Western Region Agricultural Education Research Meeting, Honolulu.

McCormack, J. (2002). Children's understandings of rurality: exploring the interrelationship between experience and understanding. Journal of Rural Studies, 18, 193-207.

McRae, K. (1990). Introduction to purposes and practices of outdoor education. In: McRae, K., Editor, 1990. Outdoor and environmental education diverse purposes and practices. Australia: The MacMillan Company.

Merriam-Webster (2012). An Encyclopædia Britannica Company. Retrieved 27.02.12, from: http://www.merriam-webster.com/dictionary/.

National Core Curriculum for Basic Education. [NCC] (2004). Finnish National Board of Education. Vammalan kirjapaino, Vammala.

Palmberg, I.E. \& Kuru, J. (2000). Outdoor activities as a basis for environmental responsibility. Journal of Environmental Education, 31, 32-36.

Palmer, J.A. (1998). Environmental Education of the 21st century: Theory, practice, progress and promise. London: Routledge.

Palmer, J. \& Neal, P. (1994). The handbook of environmental education. London: Routledge.

Patton, M.Q. (1990). Qualitative evaluation and research methods. Sage Publications, Newbury Park.

Ranta, E., Rita, H. \& Kouki, J. (1991). Biometria. Tilastotiedettä ekologeille. (Statistics for ecologists.) Yliopistopaino.
Rasila, V., Jutikkala, E. \& Mäkelä-Alitalo, A. (2003). Suomen maatalouden historia I. Perinteisen maatalouden aika. Esihistoriasta 1870-luvulle. Suomalaisen Kirjallisuuden Seura.

Rose, G. (2007). Visual Methodologies. 2nd ed. London: SAGE Publications.

Smeds, P., Jeronen, E., Kurppa, S. \& Vieraankivi, M.-L. (2011). Rural camp school eco learn: outdoor education in rural settings. International Journal of Environmental and Science Education, 6, 267-291.

Stenbacka, S. (2011). Othering the rural: about the construction of rural masculinities and the unspoken urban hegemonic ideal in Swedish media. Journal of Rural Studies, 27, 235-244.

Tuomi, J. \& Sarajärvi, A. (2004). Laadullinen tutkimus ja sisällönanalyysi. (Qualitative research and content analysis). Jyväskylä: Gummerus Kirjapaino.

Trexler, C.J. ( 2000). A qualitative study of urban and suburban elementary student understandings of pest-related science and agricultural education benchmarks. Journal of Agricultural Education, 41, 89-102.

UNESCO-UNEP (1976). The Belgrade Charter. Connect: UNESCO-UNEP Environmental Education Newsletter $1,1-2$.

UNESCO (1978). The Tbilisi Declaration: Final Report Intergovernmental Conference on Environmental Education Organized by UNESCO in cooperation with UNEP, Tbilisi, USSR, 14-26 October 1977. Connect 3,1 .

Vosniadou, S. (1994). Capturing and modelling the process of conceptual change. Learning and Instruction, 4, 45-69. 